Please do not remove this page

RMIT

UNIVERSITY

\title{
The use of reflectance measurements in the determination of diffusion of reactive dyes into cellulosic fiber
}

Khatri, Awais; White, Maxwell; Padhye, Rajiv; Momin, Nasar

https://researchrepository.rmit.edu.au/esploro/outputs/9921858918001341/filesAndLinks?institution=61RMIT_INST\&index=null

Khatri, A., White, M., Padhye, R., \& Momin, N. (2014). The use of reflectance measurements in the determination of diffusion of reactive dyes into cellulosic fiber. Color Research and Application, 39(1), 63-69. https://doi.org/10.1002/col.21764

Document Version: Submitted Version

Published Version: https://doi.org/10.1002/col.21764

Repository homepage: https://researchrepository.rmit.edu.au

(C) 2012 Wiley Periodicals, Inc.

Downloaded On 2023/04/26 22:17:53 +1000

Please do not remove this page 
Thank you for downloading this document from the RMIT Research Repository.

The RMIT Research Repository is an open access database showcasing the research outputs of RMIT University researchers.

RMIT Research Repository: http://researchbank.rmit.edu.au/

\section{Citation:}

Khatri, A, White, M and Padhye, R 2012, 'The use of reflectance measurements in the determination of diffusion of reactive dyes into cellulosic fiber', Color Research and Application, pp. 1-7.

See this record in the RMIT Research Repository at:

http://researchbank.rmit.edu.au/view/rmit:20556

Version: Submitted Version

Copyright Statement: (C) 2012 Wiley Periodicals, Inc.

Link to Published Version:

http://dx.doi.org/10.1002/col.21764 


\title{
The use of reflectance measurements in the determination of diffusion of
}

\section{reactive dyes into cellulosic fiber}

\author{
Awais Khatri ${ }^{1}$, Max White ${ }^{2}$, Rajiv Padhye ${ }^{2}$, Nasar H Momin ${ }^{2}$ \\ Department of Textile Engineering, Mehran University of Engineering and Technology, Jamshoro - \\ 76062 Sindh Pakistan \\ School of Fashion and Textiles, RMIT University, Brunswick VIC 3056 Australia \\ Correspondence to: Awais Khatri (Email: ask_textile@yahoo.com)
}

\begin{abstract}
Reactive dye fixation and color yield of a dyed cellulosic fiber significantly depend on the dye diffusion into the fiber polymer system. In case of pad dyeing processes, dye diffusion exerts a more significant influence on dye fixation and hence color yield. This paper proposes a new method for determining the extent of diffusion of reactive dyes into the fiber in pad dyeings using Kubelka-Munk equation. The $K / S$ values are used as in an equation, $\% D$ (extent of dye diffusion) $=$

$100-\left[\left(K / S_{\text {diffusion index }}\right) /\left(K / S_{\text {reference }}\right) \times 100\right]$. The paper introduces and explains how to determine the new $K / S$ variables used in this equation. The new method is simple, non-destructive, relatively faster and applicable to industrial dyehouses, and was validated by a microscopic analysis of dyed fiber cross-section carried out in this work and to the dye manufacturer's recommendations for dyebathingredient concentrations.
\end{abstract}

KEY WORDS reflectance; Kubelka-Munk; dye diffusion; reactive dyes; pad dyeing

\section{INTRODUCTION}

Pad dyeing of cellulosic fabric with reactive dyes is a two stage process. First the dye is applied to the fabric by padding. The fabric is then subjected to a dye fixation step ${ }^{1}$. The dye commences to diffuse into the interior of the fiber when the fabric is padded. The diffusion continues till the subsequent 
fixation step. The extent of the diffusion depends on the electrolyte concentration (steam fixation) or the urea concentration (bake fixation) and swelling of the fiber during fixation step ${ }^{2}$.

The selection of dyes and color matching are the most critical processes in cotton dyehouses. Color yield, the extent of dye fixation and colorfastness are the key results in these processes. However, the important goals are the shade reproducibility and right-first-time production ${ }^{3-5}$, thus producing the required quality with minimum costs including the costs involved in production time and rehandling. Dye diffusion exerts a significant influence on dye fixation, ultimate color yield and colorfastness of a dyed fiber ${ }^{6-9}$. Therefore, dye diffusion should be considered for dye selection and color matching as one of the primary parameters.

To date, industrial dyehouses have not considered the measurement of dye diffusion as an everyday tool because the currently available methods are either time consuming, indirect, or involving the use of sophisticated laboratory procedures or complex mathematics ${ }^{10,11}$. The currently available methods for determining dye diffusion are: examination of fiber or yarn cross-sections ${ }^{10}$, multilayer of a clear polymer thin film diffusion methods ${ }^{12-14}$, microdensitometer method ${ }^{15}$, rate of dyeing method ${ }^{10}$, and laser scanning confocal microscopy (LSCM) method ${ }^{16-18}$. This paper presents an easy, direct and industrially applicable method for determining the dye diffusion. The diffusion measurement can be performed during the regular spectrophotometric measurements for dye selection and color matching processes.

Reflectance spectrophotometers are now a basic feature in the laboratories of most industrial dyehouses. There they are usually used for color matching and quality control. Fundamentally, such spectrophotometers provide the means to measure the reflectance of any surface across the visible spectrum. The surface reflectance value $(R)$ can be further used for determining other primary color measurement quantities such as tristimulus values $(X Y Z), C I E L^{*} a^{*} b^{*}$ values, total color difference values and color strength value $(K / S)^{19}$.

The color strength of a dyed fabric is customarily expressed as its $K / S$ value. ' $K$ ' and ' $S$ ' are absorption and scattering coefficients of the dyed fiber. The $K / S$ value is calculated from ' $R$ ' using the Kubelka-Munk Equation $1^{20-22}$.

$K / S=(1-R)^{2} / 2 R$ 
' $R$ ' is preferably determined at the maximum absorption wavelength of the dyed fabric $\left(\lambda_{\max }\right)^{23}$. The $K / S$ value has been shown to be a direct measure of the color yield ${ }^{24}$. The value can also be used to determine other important dyeing factors such as dye uptake, migration index (MI) and dye fixation ${ }^{4,23,25-27}$. A relation between $K / S$ value and the cross-sectional distribution of dye molecules in the dyed cellulosic fibers and yarns has been reported ${ }^{28}$. Based on this fact, studies were carried out for dye diffusion in pad dyeings which resulted in a new method of measuring reactive dye diffusion into cellulosic fiber using $K / S$ values. The hypothesis for the new method is presented in following subsection. There are three basic methods for fixation of the dye after padding cellulosic fabric with reactive dyes. These are steaming (saturated steam, 30-120 sec), baking $\left(150-160^{\circ} \mathrm{C}, 30-90 \mathrm{sec}\right)$ and batching (ambient temperature, 6-36 hrs). The hypothesis was examined for these three fixation methods. The specific dyeing processes selected for the study were pad-steam, pad-dry-bake and padbatch.

\section{Hypothesis}

Immediately after padding a cellulosic fabric with a reactive dye, the dye is almost exclusively concentrated on the surface of the fibers and yarns within the fabric. As dye diffusion progresses, the number of dye molecules on the surface of the fiber becomes less and less. Consequently, the color strength $(K / S)$ value, being a measure of surface reflectance, commences to decrease. In other words there is an inverse relationship between the color strength and diffusion. As the dyeing process continues, the diffusion of the dye will eventually approach an optimum level and the dye will be distributed throughout the fiber. It was hypothesised that a measure of diffusion could be obtained through using $K / S$ values obtained at various stages of the dyeing process. These measurements would need to be made before any washing-off because this removes unfixed dye from the surface and interior of the fiber. The base value for the measure of diffusion should ideally represent the color strength of the dyed fabric where effectively no dye diffusion has occurred. For this purpose, if the fabric is padded with dyebath containing the dye only, the diffusion will be at minimum and there will be the maximum number of dye molecules on the surface of the fiber. The color strength value measured at this point was taken as the base or reference value. That value is represented by ' $K / S_{\text {reference }}$. The color strength value of a dyed fabric where certain diffusion has occurred because of 
either fixation step or using the auxiliaries (such an electrolyte, urea, alkali, antimigrant...etc) is represented by ' $K / S_{\text {diffusion index }}$ '. This value is obtained sometime later in the dyeing process after padding the fabric in a dyebath with or without auxiliaries before washing-off. Having known the $K / S_{\text {reference }}$ and $K / S_{\text {diffusion index }}$ values, a measure of diffusion can be calculated by using following equation:

$\% D=100-\left[\left(K / S_{\text {diffusion index }}\right) /\left(K / S_{\text {reference }}\right) \times 100\right]$

Where ' $\left(K / S_{\text {diffusion index }}\right) /\left(K / S_{\text {reference }}\right) \times 100$ ' represents the percentage of the dye remaining on the surface of the fiber after a certain amount of dye diffusion has occurred. Ideally, $K / S_{\text {diffusion index }}$ will be equal to $K / S_{\text {reference, }}$ when there is no dye diffusion.

\section{EXPERIMENTAL}

\section{Materials}

A commercially bleached, un-mercerized and fluorescent brightener-free cotton cellulose woven fabric $\left(282 \mathrm{~g} / \mathrm{m}^{2}\right)$ with an absorbency of $1 \mathrm{sec}($ AATCC $79-1995)$ and a CIE whiteness index of 78.6 was used. Commercial reactive dyes, Clariant's Drimarene Red K4BL (CI Reactive Red 147, difluorochloropyramidine reactive group), Dystar's Remazol Navy RGB 150\% (CI Reactive Blue 250, sulphatoethylsulphone reactive group) and Kisco's Synozol Blue SHF-BRN 150\% (CI Reactive Blue 221, bifunctional reactive group: aminochlorotriazene + sulphatoethylsulphone) were used. A non-ionic emulsifying detergent (Felosan RGN-S, CHT) was used for washing-off of unfixed reactive dyes and Alginate NVS (CHT) was used as an anti-migrant for pad-dry-bake dyeing. All other chemicals were general laboratory grade.

\section{Methods}

\section{Pad dyeings}

Fabric samples were dyed by padding (two dip-two nip, 70\% liquor pick-up, Benz laboratory padder) with $20 \mathrm{~g} / \mathrm{l}$ dye and dye manufacturers recommended padding chemicals (see Table I). For pad steam dyeing, the padded fabric samples were steamed (wet-temperature of $101-102^{\circ} \mathrm{C}, 100 \%$ moisture, Mathis laboratory steamer) for $60 \mathrm{sec}$. For pad-dry-bake dyeing, the samples were dried $\left(70^{\circ} \mathrm{C}\right.$, suspended in a Brownbuilt automatic oven dryer) followed by baking $\left(160^{\circ} \mathrm{C}\right.$ for CI Reactive Red 
$147,150^{\circ} \mathrm{C}$ for CI Reactive Blue 250 and CI Reactive Blue 221, Mathis laboratory stenter) for $60 \mathrm{sec}$. For pad-batch dyeing, the samples were carefully rolled, wrapped with plastic and left to batch (ambient temperature, $25 \pm 2^{\circ} \mathrm{C}$ ) for $12 \mathrm{hrs}$. Dyeings were also carried out to study the effect of variation in the magnitudes of sodium chloride concentration ( $0-60 \mathrm{~g} / \mathrm{l}$, pad steam dyeing), steaming and baking time $(0-120 \mathrm{sec})$, batching time (0-24 hrs) and dye concentration $(0-20 \mathrm{~g} / \mathrm{l}$ in pad-steam dyeing, $0-30 \mathrm{~g} / 1$ in pad-batch dyeing).

\section{Washing-off and DMF stripping}

Dyed fabrics were rinsed with cold then hot tap water, soaped with $2 \mathrm{~g} / 1$ Felosan RGN-S at the boil for $15 \mathrm{~min}$, and then rinsed with hot water until the bleeding stopped. The fabrics were finally rinsed with cold water and dried. The dye fixation was measured after further boiling the fabrics with a $50 \%$ aqueous solution of N,N-dimethyl formamide, DMF, (liquor-to-fiber ratio of 40:1, 15 min, reflux condensation).

\section{Measurements}

\section{Color strength $(\mathrm{K} / \mathrm{S})$ value}

$K / S$ value was obtained at the maximum absorption peak (Datacolor 600 spectrophotometer settings: $30 \mathrm{~mm}$ sample aperture, illuminant D65, UV included, specular component included, reflectance mode and $1964\left(10^{\circ}\right)$ CIE Supplementary Standard Observer). Each fabric sample was conditioned (30 $\mathrm{min}, \sim 25^{\circ} \mathrm{C}, \sim 65 \%$ relative humidity) before measuring the $K / S$ value.

\section{Color yield and dye fixation}

The color strength after DMF treatment $\left(K / S_{D M F}\right)$ was obtained as the final color yield. The approach for determining the extent of reactive dye fixation using $K / S$ values, used by other researchers ${ }^{29-32}$, was followed. The percentage of reactive dye fixed on the cotton fabric $(\% F)$ was measured as the per cent ratio of the final color yield to the color strength of dyed sample before washing-off.

\section{Cross-section of dyed fiber}

The sections of dyed yarn bundles were prepared on thin steel plate having $1 \mathrm{~mm}$ holes. This was done by pulling the bundle of yarns through the hole, using a strong nylon yarn, so that the yarns were tightly packed. The cross-sections were then revealed by slicing them off on the metal surface. The microscopic observations were made (500 times magnification, Leica DM 2500M Microscope). 


\section{Procedures for the proposed method of measuring diffusion}

\section{Determining $\boldsymbol{K} / \boldsymbol{S}_{\text {reference }}$}

The fabric sample was padded with a known concentration of the dye (two dip-two nip, 70\% liquor pick-up, Benz laboratory padder). The preparation of the dye solution and setting up the liquor pickup were precisely done. The sample was then dried $\left(15 \mathrm{~min}, 70^{\circ} \mathrm{C}\right.$, suspended in a Brownbuilt automatic oven dryer). Drying, in the absence of an electrolyte, urea or antimigrant, results in maximum number of dye molecules on the surface of the fabric because the dye solution migrates to the surface of the fabric as reported by Hunger ${ }^{1}$. The color strength $\left(K / S_{\text {reference }}\right)$ was then measured. It required only several hours to prepare the database reference color strength values. Those values can be used for dye diffusion measurements repeatedly for the same dye and fabric.

\section{Determining $K / S_{\text {diffusion index }}$}

Having determined the ' $K / S_{\text {reference }}$ ', an undyed sample of the same fabric was padded with the dyebath containing the same concentration of the same dye together with known concentrations of the relevant auxiliaries in the same precised way. The color strength $\left(K / S_{\text {diffusion index }}\right)$ was then measured before and after the subsequent fixation steps (steaming, baking or batching).

\section{RESULTS AND DISCUSSION}

\section{Effect of electrolyte concentration on dye diffusion (pad-steam dyeing)}

In pad-steam dyeing, an electrolyte favours increased dye levelness in the fiber and the eventual color yield ${ }^{33-35}$. This is because the electrolyte promotes dye diffusion, even distribution of dye molecules throughout the fiber and ultimately dye fixation ${ }^{6}$. Therefore, pad-steam dyeing results were obtained to determine the effect of electrolyte concentration on dye diffusion.

\section{Microscopic analysis}

Fiber cross-sections of the fabrics dyed with CI Reactive Red 147 showed that the core is more colored with increasing electrolyte concentration (Figure 1). This confirms that the electrolyte promotes dye diffusion in pad-steam reactive dyeing of cotton ${ }^{6,9,34,36-38}$. 


\section{New method for the extent of dye diffusion (\%D)}

Figure 2 shows the comparative effect of electrolyte concentration on color strength of dyed sample before washing-off $\left(K / S_{\text {diffusion index }}\right)$ and the proposed measure of dye diffusion $(\% D)$ using equation (1). The figure shows an inverse relation between $K / S_{\text {diffusion index }}$ and $\% D$. Figure 2 (b) shows that the dye diffusion increases with increasing sodium chloride concentration, at constant alkali concentration $(15 \mathrm{~g} / \mathrm{l})$ and steaming time $(60 \mathrm{sec})$. Maximum dye diffusion was obtained at $50 \mathrm{~g} / 1$ sodium chloride. It is well known that the addition of an electrolyte in a dyebath increases the degree of aggregation of the dye molecules ${ }^{39}$. Therefore, an optimum electrolyte concentration generally exists. Electrolyte concentrations higher than the optimum are avoided to minimise excessive dye aggregation. The CI Reactive Blue 250 diffused less than the CI Reactive Red 147 and the CI Reactive Blue 221. The dyefiber reaction and dye diffusion occur simultaneously in pad-steam dyeing. Therefore, CI Reactive Blue 250 may have higher relative rate of dye-fiber reaction to the rate of dye diffusion.

\section{Effect of electrolyte concentration on dye fixation and color yield}

Figure 3 shows that the dye fixation and color yield increase with increasing sodium chloride concentration, at constant alkali concentration $(15 \mathrm{~g} / \mathrm{l})$ and steaming time $(60 \mathrm{sec})$. The maximum values were obtained at $50 \mathrm{~g} / 1$ sodium chloride, after which a near-constant color yield was observed with CI Reactive Red 147. The optimum dye diffusion was also obtained at $50 \mathrm{~g} / \mathrm{l}$ sodium chloride; therefore, it can be postulated that the dye fixation and color yield increase with the increase in dye diffusion. Further, the optimum dye fixation and color yield can be obtained at optimum dye diffusion. Thus, the optimum electrolyte concentration can be determined by obtaining optimum dye diffusion instead of obtaining dye fixation and color yield. This saves the experimental time as washing-off procedures are not required for determining dye diffusion.

\section{Relation of dye diffusion to the dye fixation and color yield (pad-steam dyeing)}

The relationship between the extent of dye diffusion and dye fixation (and hence color yield) can be obtained through results presented in Figures 2 (b) and 3. The increase in dye diffusion is known to favour dye fixation and color yield in pad dyeings ${ }^{6}$. Figure 4 shows that the proposed measure of diffusion is directly related to dye fixation and color yield. This further confirms the validity of the new method for determining the extent of dye diffusion. 


\section{Rate of dye diffusion during steaming, baking and batching}

Figure 5 shows the extent of dye diffusion achieved at an industrially possible range of steaming times for CI Reactive Red 147, CI Reactive Blue 250 and CI Reactive Blue 221. For the CI Reactive Blue 250, the dye diffusion did not increased significantly with increasing steaming duration. Over $95 \%$ of its diffusion occurred within the first 30 seconds. The diffusion slightly increased up to a maximum at 60 seconds and slightly decreased at longer steaming time. This implies that the dye has higher dye diffusion initially when the extent of dye-fiber reaction is low. For the CI Reactive Red 147 and the CI Reactive Blue 221, a pronounced maximum value for $\% D$ was observed at 60 seconds of steaming time. This shows that the rate of diffusion of these dyes, relative to CI Reactive Blue 250, was expedited more by steaming. The diffusion maxima may be due to excessive dye hydrolysis with increasing steaming time and the hydrolysed dye is relatively more mobile within the fiber. However, the reasons for the maxima are not fully understood which may have industrial implications. The effect of dye molecular weight and the type and number of reactive groups may be worthy of further study.

For the pad-dry-bake method, Figure 6 shows that the patterns of behaviour of dye diffusion with baking time are similar to those obtained with steaming time. The absolute values of diffusion of the three dyes at any time were less with baking than with steaming. This implies the presence of water molecules in the cotton fiber at elevated temperatures has a marked effect on the rate and extent of diffusion. For the CI Reactive Blue 250, dye diffusion continued to increase marginally with increasing baking time. The maximum value for this dye was not determined because the time exceeds the industrial practice. Whereas the diffusion of CI Reactive Red 147 and CI Reactive Blue 221 increased up to 90 seconds of baking time and then decreased.

Figure 7 demonstrates the applicability of the proposed method for determining diffusion to the padbatch dyeing method. There, the extent of diffusion of CI Reactive Red 147 and CI Reactive Blue 221 dyes increase then decrease with increasing batching time. The maximum value of diffusion was obtained at $12 \mathrm{hrs}$ batching. For the CI Reactive Blue 250, diffusion continued to increase with increasing batching time. The maximum value for CI Reactive Blue 250 is of the order of 36 hrs of batching. As per the dye manufacturers' recommendations for optimum dyeing results, the batching 
time for CI Reactive Red 147 and CI Reactive Blue 221 ranges from 4 to $14 \mathrm{hrs}$ and that for CI Reactive Blue 250 is up to $36 \mathrm{hrs}$. The figure confirms that the dyeing results significantly depend on the extent of dye diffusion and conforms to the dye manufacturers' recommendations.

It is clear from Figures 5, 6 and 7 that the dye diffusion is promoted by steaming, baking and batching. The CI Reactive Blue 250 diffuses more slowly than the other two dyes. Figure 8 shows that the optimum dye diffusion obtained in pad-steam and pad-batch dyeings was similar and considerably higher than that obtained in pad-dry-bake dyeing. This reflects that the penetration of dye molecules is supported by the presence of water molecules which are not present in pad-dry-bake process.

\section{Effect of dye concentration on diffusion}

The effect of dye concentration on diffusion was determined for the pad-steam and pad-batch processes as these processes showed a significant extent of dye diffusion. In kinetic studies, dye concentration dependence is an important factor because an increase in the number of dye molecules results in increasing the competition for dye sites on the fiber. Most of such studies have been of theoretical nature where diffusion coefficients are demonstrated for exhaust dyeings ${ }^{6,13,15,40,41}$. In exhaust dyeing of cotton with anionic dyes, dye exhaustion gradually decreases with an increase in the concentration of dyes applied. This is due to the gradual build-up of the dye at the fiber surface, hence retarding the further adsorption of remaining dye from the dyebath ${ }^{42}$. The effect of dye concentration on the extent of dye diffusion as determined by the proposed equation for pad dyeings is shown in Figure 9. The results show that the dye diffusion decreases with increasing dye concentration in both pad-steam and pad-batch dyeings. In order to obtain optimum dyeing results, increased amounts of electrolyte may be used for increased dye concentrations, and that is also recommended by dye manufacturers.

\section{CONCLUSION}

The new, simple, non-destructive and relatively faster, method for determining the extent of dye diffusion by using $K / S$ values have been developed and validated for pad dyeings. The results obtained by new method conform to a microscopic analysis of dyed fiber cross-section carried out in this work and to the dye manufacturer's recommendations for dyebath-ingredient concentrations. This 
can effectively be used in industrial dyehouses for precise determination of the dye efficiency and thus improving dyeing results and assisting with cost reductions.

\section{ACKNOWLEDGEMENTS}

We gratefully thank Mr M Fergusson, School of Fashion \& Textiles RMIT University, for his technical advice and suggestions.

\section{REFERENCES}

1. Textile dyeing. In: Hunger K, editor. Industrial Dyes. Third ed: Wiley-VCH; 2003. p 339357.

2. Kissa E. Urea in reactive dyeing. Textile Research Journal 1969;39(8):734-741.

3. Bradbury MJ, Collishaw PS, Moorhouse S. Reactive dye selection and process development for exhaust dyeing of cellulose. Textile Chemist and Colorist 1995;27(8):19-23.

4. Collishaw PS, Phillips DAS, Bradbury MJ. Controlled coloration: a success strategy for the dyeing of cellulosic fibers with reactive dyes. Journal of the Society of Dyers and Colorists 1993;109(9):284-292.

5. Collishaw PS, Bradbury MJ, Bone JA, Hyde RF. Controlled coloration using high performance reactive and disperse dyes. Book of Papers, International Conf. and Exhibition AATCC, Atlanta, 1997 1997:353-365.

6. Krichevskii GE, Movshovich IM. Use of methods of heterogeneous chemical kinetics and nonequilibrium thermodynamics for the quantitative evaluation of the rate of fixation of reactive dyes by fibrous materials. Textile Research Journal 1970;40(9):793-802 .

7. Aspland JR. Reactive dyes and their application. Textile Chemist and Colorist $1992 ; 24(5): 31-36$.

8. Suss-Leonhardt J, McKelvey D, Pesch B. New developments in cold pad batch dyeing. Melliand International 2006;12(3):233-235.

9. Shore J. Dyeing with reactive dyes. In: Shore J, editor. Cellulosics Dyeing. First ed: Society of Dyers and Colorists; 1995. p 189-245. 
10. Dawson TL, Todd JC. Dye diffusion - The key to efficient coloration. Journal of Society of Dyers and Colorists 1979(December):417-426.

11. Rys P, Zollinger H. Reactive dyeing: basic principles and their implications for the dyer. Textile Chemist and Colorist 1973;6(3):35-40.

12. Sekido M, Matsui K. Method of the determination of surface concentration and diffusion coefficient by cylindrical cellophane film roll. Sen-i Gakkaishi 1964;20:778.

13. Motomura H, Morita Z. Diffusion with simultaneous reaction of reactive dyes in cellulose. Journal of Applied Polymer Science 1977;21(2):487-499.

14. Hamoudeh M, Schonpflug E. Prüfung der färberischen Eigenschaften und der Kombinierbarkeit der Palanil-Farbstoffe nach dem BASF-Kombi-Test. Melliand Textilberichte 1971;52(9):1063-1068.

15. Peters RH, Petropoulos JH, McGregor R. A Study of the Diffusion of Dyes in Polymer Films by a Microdensitometric Technique. Journal of Society of Dyers and Colorists 1961;77:704-712.

16. Song Y, Srinivasarao M, Tonelli A. Study of dye diffusion in fibers by laser scanning confocal microscopy. Macromolecular Symposia 1999;148:395-402.

17. Song Y, Srinivasarao M, Tonelli A, Balik CM, McGregor R. Laser scanning confocal microscopy study of dye diffusion in fibers. Macromolecules 2000;33(12):4478-4485.

18. Wang C, Zhu L, Qiu Y. Laser scanning confocal microscope characterization of dye diffusion in nylon 6 fibers treated with atmospheric pressure plasmas. 107: Wiley Subscription Services, Inc., A Wiley Company; 2008. p 1471-1478.

19. McDonald R. Color Physics for Industry. Society of Dyers and Colorists; 1997.

20. Blackburn RS, Burkinshaw SM. Treatment of cellulose with cationic, nucleophilic polymers to enable reactive dyeing at neutral $\mathrm{pH}$ without electrolyte addition. Journal of Applied Polymer Science 2003;89(4):1026-1031.

21. Mouxiou E, Eleftheriadis I, Nikolaidis N, Tsatsaroni E. Reactive dyeing of cellulosic fibers: use of cationic surfactants and their interaction with reactive dyes. Journal of Applied Polymer Science 2008;108(2):1209-1215. 
22. Ahmed NSE. The use of sodium edate in the dyeing of cotton with reactive dyes. Dyes and Pigments 2005;65(3):221-225.

23. Becerir B. A novel approach for estimating the relation between $\mathrm{K} / \mathrm{S}$ value and dye uptake in reactive dyeing of cotton fabrics. Fibers and Polymers 2005;6(3):224-228.

24. Suesat $\mathrm{J}$. The influence of $\mathrm{NaCl}$ concentration on the build-up properties and aggregation of reactive dyes. Kasetsart Journal - Natural Science 2008;42(3):558-568.

25. Chattopadhyay DP, Chavan RB, Sharma JK. Salt-free reactive dyeing of cotton. International Journal of Clothing Science and Technology 2007;19(2):99-108.

26. Ahmed N, Oulton DP, Taylor JA. The use of reflectance measurements in the determination of fixation of reactive dyes to cotton. Color Research \& Application 2006;31(2):117-121.

27. Bradbury MJ, Collishaw PS, Phillips DAS. The exceL concept for the dyeing of cellulose fibers with Procion H-EXL dyes. Journal of the Society of Dyers and Colorists $1992 ; 108(10): 430-435$.

28. Goswami P, Blackburn R, Taylor J, White P. Dyeing behaviour of lyocell fabric: effect of $\mathrm{NaOH}$ pre-treatment. Cellulose 2009;16(3):481-489.

29. Ahmed NSE, Youssef YA, El-Shishtawy RM, Mousa AA. Urea/alkali-free printing of cotton with reactive dyes. Coloration Technology 2006;122(6):324-328.

30. Bairagi N, Gulrajani ML, Deopura BL, Shrivastava A. Dyeing of N-modified viscose rayon fibers with reactive dyes. Coloration Technology 2005;121(3):113-120.

31. Kamel MM, El-Shishtawy RM, Hanna HL, Ahmed NSE. Ultrasonic-assisted dyeing: I. Nylon dyeability with reactive dyes. Polymer International 2003;52(3):373-380.

32. Hyung-Min C. One-bath dyeing and nonformaldehyde durable press finishing of cotton using dialdehyde and a monochlorotriazinyl reactive dye. Textile Research Journal 2002;72(6):469.

33. Reactive dyes. In: Broadbent AD, editor. Basic Principles of Textile Coloration. First ed: Society of Dyers and Colorists; 2005. p 332-357.

34. Aspland JR. Practical application of reactive dyes. Textile Chemist and Colorist $1992 ; 24(6): 35-40$. 
35. Phillips DAS. The dyeing of cellulosic fibers with reactive dyes. Advances in Color Science and Technology 1998;1:1-11.

36. Broadbent AD. Basic Principles of Textile Coloration. Society of Dyers and Colorists; 2005.

37. Dolby PJ. Dyeing of cellulosic fibers with reactive dyes. Textile Chemist and Colorist 1977;9(11):264-268 .

38. Rusznak I, Zobor J, Levai G. Kinetic investigation of reactive dyeing. Dyes and Pigments 1981;2(4):285-303.

39. Hamlin JD, Phillips DAS, Whiting A. UV/Visible spectroscopic studies of the effects of common salt and urea upon reactive dye solutions. Dyes and Pigments 1999;41(1-2):137142.

40. Rosenbaum S, Goodwin FL. Concentration dependence in dye diffusion. Journal of Applied Polymer Science 1965;9(1):333.

41. Lin SH. Concentration-dependent diffusion of dye in reactive dyeing systems. Journal of Applied Polymer Science 1992;44(10):1743-1749.

42. Lewis DM. Dyestuff-fiber interactions. Review of Progress in Coloration and Related Topics 1998;28:12-17. 
TABLE I Padding Chemicals and Concentrations

\begin{tabular}{|c|c|c|c|}
\hline \multirow[t]{2}{*}{ Dye } & \multicolumn{3}{|c|}{ Chemicals and their concentrations } \\
\hline & Pad-steam dyeing & Pad-dry-bake dyeing & Pad-batch dyeing \\
\hline Cl Reactive Red 147 & $\begin{array}{l}\text { Sodium chloride }(30 \mathrm{~g} / \mathrm{l}) \\
\text { Sodium bicarbonate }(15 \mathrm{~g} / \mathrm{l})\end{array}$ & $\begin{array}{l}\text { Urea }(100 \mathrm{~g} / \mathrm{l}) \\
\text { Sodium bicarbonate }(15 \mathrm{~g} / \mathrm{l}) \\
\text { Alginate NVS }(1 \mathrm{~g} / \mathrm{l})\end{array}$ & $\begin{array}{l}38^{\circ} \mathrm{Be} \text { Sodium hydroxide }(8 \mathrm{ml} / \mathrm{l}) \\
\text { Sodium carbonate }(10 \mathrm{~g} / \mathrm{l})\end{array}$ \\
\hline Cl Reactive Blue 250 & $\begin{array}{l}\text { Sodium chloride }(30 \mathrm{~g} / \mathrm{l}) \\
\text { Sodium carbonate }(15 \mathrm{~g} / \mathrm{l})\end{array}$ & $\begin{array}{l}\text { Urea }(50 \mathrm{~g} / \mathrm{l}) \\
\text { Sodium carbonate }(15 \mathrm{~g} / \mathrm{l}) \\
\text { Alginate NVS ( } 1 \mathrm{~g} / \mathrm{l})\end{array}$ & $\begin{array}{l}38^{\circ} \mathrm{Be} \text { Sodium hydroxide }(14 \mathrm{ml} / \mathrm{l}) \\
\text { Sodium silicate }(70 \mathrm{~g} / \mathrm{l})\end{array}$ \\
\hline Cl Reactive Blue 221 & $\begin{array}{l}\text { Sodium chloride }(30 \mathrm{~g} / \mathrm{l}) \\
\text { Sodium carbonate }(15 \mathrm{~g} / \mathrm{l})\end{array}$ & $\begin{array}{l}\text { Urea }(50 \mathrm{~g} / \mathrm{l}) \\
\text { Sodium carbonate }(15 \mathrm{~g} / \mathrm{l}) \\
\text { Alginate NVS }(1 \mathrm{~g} / \mathrm{l})\end{array}$ & $\begin{array}{l}38^{\circ} \mathrm{Be} \text { Sodium hydroxide }(12 \mathrm{ml} / \mathrm{l}) \\
\text { Sodium chloride }(30 \mathrm{~g} / \mathrm{l})\end{array}$ \\
\hline
\end{tabular}



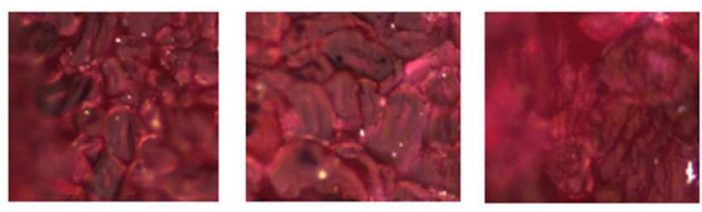

0 g/ Sodium chloride

$20 \mathrm{~g} / \mathrm{S}$ Sodium chloride

$40 \mathrm{~g} / \mathrm{S}$ Sodium chloride

FIGURE 1 Fibre cross-sections of cotton fabrics dyed with $20 \mathrm{~g} / 1 \mathrm{CI}$ Reactive Red 147 (before washing-off) at $60 \mathrm{sec}$ steaming. 


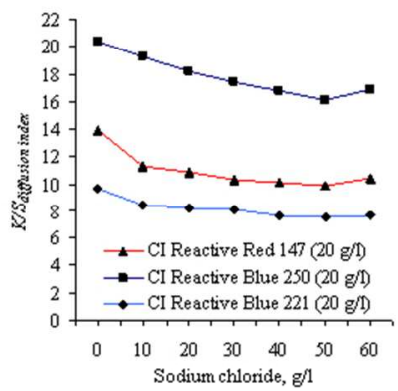

(a)

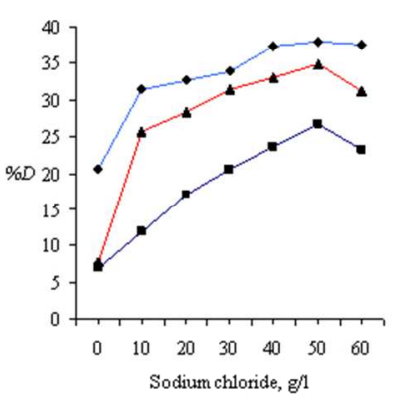

(b)

FIGURE 2 Effect of electrolyte concentration on dye diffusion 

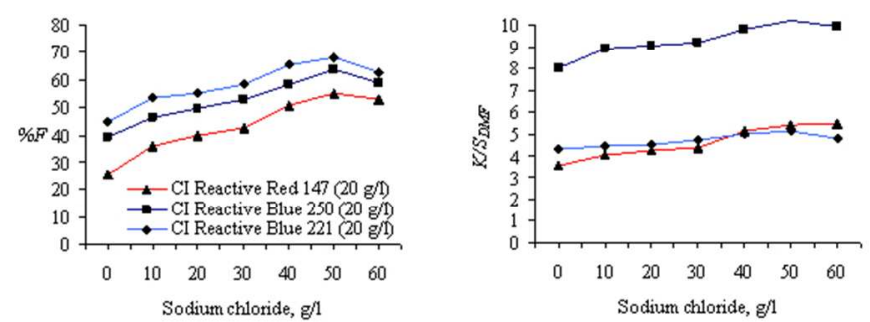

FIGURE 3 Effect of electrolyte concentration on dye fixation and colour yield 

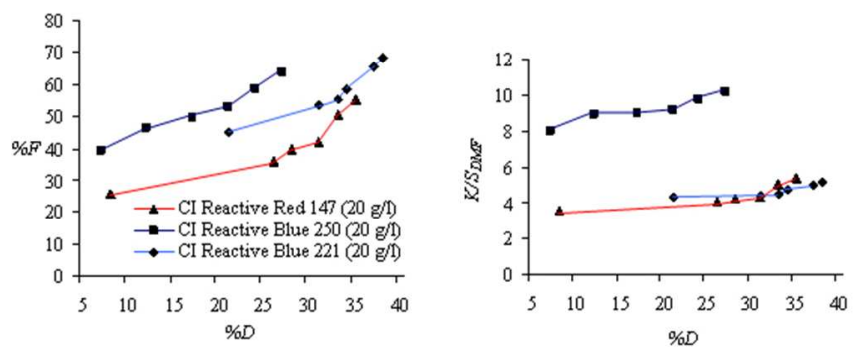

FIGURE 4 Effect of dye diffusion on dye fixation and colour yield 
1

2

3

4

5

6

7

8

9

10

11

12

13

14

15

16

17

18

19

20

21

22

23

24

25

26

27

28

29

30

31

32

33

34

35

36

37

38

39

40

41

42

43

44

45

46

47

48

49

50

51

52

53

54

55

56

57

58

59

60

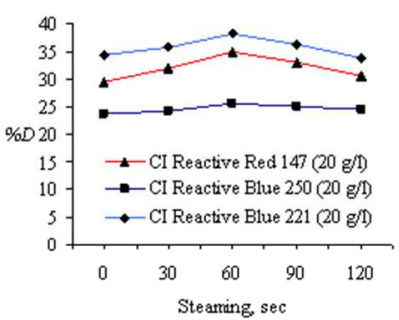

FIGURE 5 Rate and extent of dye diffusion during steaming 
8 
1

2

3

4

5

6

7

8

9

10

11

12

13

14

15

16

17

18

19

20

21

22

23

24

25

26

27

28

29

30

31

32

33

34

35

36

37

38

39

40

41

42

43

44

45

46

47

48

49

50

51

52

53

54

55

56

57

58

59

60

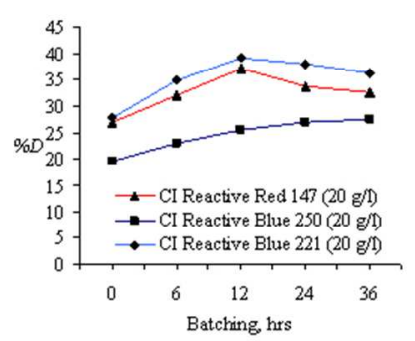

FIGURE 7 Rate and extent of dye diffusion during batching

$190 \times 275 \mathrm{~mm}(96 \times 96 \mathrm{DPI})$ 


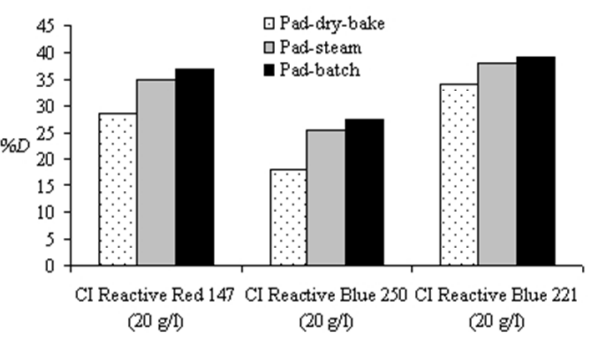

FIGURE 8 Optimum dye diffusion obtained with steaming, baking and batching 
